\title{
The influence of SPI on business success in software SMEs: An empirical study
}

\author{
Paul Clarke ${ }^{1,2}$ and Rory V. O'Connor ${ }^{2,3}$ \\ ${ }^{1}$ Lero Graduate School in Software Engineering, Dublin City University, Ireland. \\ ${ }^{2}$ Dublin City University, Ireland. \\ ${ }^{3}$ Lero, the Irish Software Engineering Research Centre.
}

\begin{abstract}
In this paper, we present the findings of a study into the relationship between software process improvement (SPI) and business success in software development small- to medium- sized companies (software SMEs). A number of earlier related studies investigated the benefits of SPI in software SMEs, particularly in terms of improvements in product quality and adherence to budgetary and schedule constraints. However, only limited or indirect research has examined the relationship between SPI and business success. In this study, we adopt the Holistic Scorecard (HSC) (Sureshchandar and Leisten, 2005) as a business success reference framework, thus examining both the financial and the non-financial aspects of business success. In addition, we utilise ISO/IEC 12207 (ISO/IEC, 2008) as a comprehensive reference framework for the investigation of SPI activity in software SMEs. Through the use of new metrics introduced in this paper, the study findings establish that there is a positive association between SPI and business success in software SMEs, highlighting the importance of SPI in successful software SMEs. This is the first time that this relationship has been demonstrated using empirical data, and therefore, the findings represent a valuable new addition to the body of knowledge.
\end{abstract}

KEYWORDS: Software Process Improvement, Business Success.

\section{Introduction}

Business processes are the logical organization of people, materials, energy, equipment, and procedures into work activities designed to produce a specified end result (work product) (Pall, 1987). Such processes are considered to be important because they affect the quality of the products and services that the organization delivers to its clients; with an effective business process producing high-quality products in a cost effective way (Cugola, 1998). While some debate exists in relation to the degree of importance of business processes in enabling business success (Vergidis et al., 2008), various empirical studies have supported the view that business processes (and business process improvement) are important for business performance (McCormack and Johnson, 2001, Skrinjar et al., 2008). Moreover, the importance of business processes is acknowledged by the inclusion of business process performance perspectives in many of the contemporary business performance measurement frameworks (Kaplan and Norton, 1992, Neely et al., 2002). The Holistic Scorecard (HSC) (Sureshchandar and Leisten, 2005), a software development specific extension of the popular Balance Scorecard (BSC) (Kaplan and Norton, 1992) performance management framework, includes a distinct business process perspective.

In software development organisations, the software development process is a large and complex component of the overall business process and therefore, along with other business processes, effective management of the software development process should support the achievement of business success. SPI involves the improvement of the software development process and is therefore concerned with the effectiveness of the process. However, to date the relationship between SPI and business success in software SMEs has received little attention, 
with no earlier study being dedicated directly to an in-depth examination of the relationship between SPI and business success in software SMEs. As a result, there is a lack of solid empirical data regarding the relationship between the amount of SPI conducted by an organisation (which we term SPI activity) and business success in software SMEs. Business processes, including the software development process, exist so as to support the business in fulfilling its objectives. Business process improvement, including SPI, is concerned with improving the method of work, which should ultimately have the consequence of improved business success. Therefore, SPI should be positively associated with business success. However, for software SMEs, there is no empirical evidence supporting this relationship at present. Consequently, the authors believe that it is important to examine if SPI activity is having a positive effect on business success in software SMEs and we have developed the following hypothesis as a focus for this study:

\section{Hypothesis: Increased SPI activity is positively associated with increased business success.}

The remainder of this paper is structured as follows: section two identifies the related research while in section three, the study design is presented. In section four, the data collection phase is outlined, with section five presenting a description of the quantification procedures for business success and SPI activity. Section six provides details of the data analysis. Section seven discusses the impact of the findings and a conclusion is presented in section eight.

\section{Related work}

There are many direct and indirect benefits from SPI (Zahran, 1998), and often these can be difficult to measure (Rozum, 1993, Mathiassen et al., 2005). They include increases in productivity, product quality and customer satisfaction, improvements to budget and schedule adherence and decreases in costs, cycle times and process complexity. Rico (2004) presents an approach for translating these benefits into monetary terms and comparing the investment with the return, or in other words calculating the financial Return On Investment (ROI). However, in practice, ROI is inconsistently calculated, resulting in confusion and general scepticism (Erdogmus et al., 2004). In spite of this, some research has investigated the ROI associated with SPI, with Van Solingen (2004) presenting a review of several such studies that were carried out in large development organisations - determining that the average ROI for SPI is 7:1, i.e. for every one dollar invested, seven dollars are returned.

Much of the literature of SPI-related financial ROI is centred on studies in large organisations - as demonstrated by the company listing presented by Van Solingen (2004). While comparable information for small software development companies is less evident, they can derive benefits from SPI (Kautz, 1998). Sanders (1998) examines the benefits accruing to small software development organisations from SPI: Cunav significantly reduces the rework effort by improving the requirements capture process while Peregrine increases overall capability by investing in source code and defect management processes. Another study of SPI in small organisations concludes that it is possible to implement software processes in a beneficial and cost-efficient manner considering their specific business goals, characteristics, and resource limitations (Von Wangenheim et al., 2006). While Sanders (1998) and Von Wangenheim et al. (2006) demonstrate that SPI can make a significant contribution to improving software development in small companies, there is no attempt to examine the association between SPI and the successful achievement of business goals. 
In a related study by Cater-Steel and Rout (2008), process improvement is reported to have a positive long-term effect on businesses. However, by focusing just on traditional views of business success, such as financial and headcount measures, they lack a comprehensive examination of the broader business success considerations for software development organisations (such as presented in the HSC (Sureshchandar and Leisten, 2005)). Furthermore, they also lack the type of multi-phased business success examination that is necessary to guard against false or biased recollection on the part of interviewees (a point that is discussed in more detail in section 3.1.1).

Other studies also demonstrate the benefits of SPI in small organisations. Ferreira et al. (2007) show that BL Informatica successfully grows its headcount through the successive implementation of quality management standards and process maturity reference models, including ISO-9000 (ISO, 2004) and CMMI (SEI, 2006). However, as previously identified, these approaches may not be well suited to the needs of small companies in general (Miluk, 2005, El Emam and Birk, 2000) and evidence suggests that SMEs have not widely adopted such approaches (Coleman and O'Connor, 2008, McConnell, 2002, Pino et al., 2008). Moreover, the work presented in Ferreira et al. (2007) does not attempt to correlate SPI actions with business success.

Fleck (2004) proposes that requirements documentation, change control and communication are among the most important process activities - but the study, which presents a light-weight development process for very small organisations, is carried out in just one company. In other research focused on a single SME, Biro et al. (2000) find that, owing to SPI initiatives, MemoLuX is able to reduce production costs while at the same time increasing business. Further evidence of the benefits of a light-weight SPI approach to a single SME are presented in Scott et al. (2002) where improvements in project estimation and customer relations are observed. However, along with Fleck (2004) and Biro et al. (2000), Scott et al. (2002) does not attempt to examine the relationship between SPI and a broad spectrum of business objectives.

Deephouse et al. (1995) use a multiple-company survey to investigate the effectiveness of individual process activities, finding that effective planning and cross-functional teams are regarded as being of major importance to project outcomes. The respondents are described as being experienced software engineers from a range of large and small companies, meaning that Deephouse et al. (1995) lack a specific SME focus. In addition, there is no attempt to investigate the influence of SPI on the achievement of business goals - but rather on the successful outcome of a specific project.

While the benefits of SPI to SMEs have been demonstrated through studies such as those in the preceding paragraphs, Niazi (2006) concludes that much more evidence in favour of SPI for SMEs is required in order to justify a commitment to SPI programmes. In more recent works, Niazi et al. (2008) and Niazi and Babar (2009) attempt to establish the perceived value of the specific practices of the following CMMI level 2 process areas: requirements management, process and product quality assurance and configuration management. These studies acknowledge the need for finer granularity in relation to the perceived value of different software processes and SPI practices. However, the restriction in study implementation to just a subset of the CMMI level 2 practices raises an issue in that it has been claimed that such practices are not necessarily of primary benefit to small companies (Von Wangenheim et al., 2006). Consequently, the framework underlying the studies carried out by Niazi, Babar and Ibrahim (2008) and Niazi and Babar (2009) may not represent the most appropriate point of departure for research into the key practices for small software 
development companies. Moreover, Niazi, Babar and Ibrahim (2008) and Niazi and Babar (2009) do not attempt to examine the relationship between SPI and business success.

The various works discussed above demonstrate that SPI activities can deliver benefits for software development projects and organisations. Predominately, these earlier studies have examined the benefits of SPI in terms of improvements in software quality, or other desirable outcomes, including greater budgetary and schedule adherence. However, these earlier works lack a thorough investigation of the broad spectrum of business success considerations for software development companies. Furthermore, they are not directly focused on examining the relationship between SPI and business success. As a result, there is a significant deficiency of empirical data regarding the relationship between business success and SPI in software SMEs.

By examining the broad extent of SPI activity in a number of SMEs (and not just individual SPI activities in individual settings), we seek to examine the general relationship between the extent of SPI activity and the extent of business success. Business process theory informs us that business processes are an important consideration for business success and therefore, the improvement of the specifics of the software development process should be a consideration for business success in software development companies. However, to date no study has attempted to directly and empirically examine the relationship between SPI and business success in software SMEs. The authors believe that it is important to examine this relationship, since evidence of a positive association between SPI activity and business success would greatly improve the motivation for SPI in software SME. Such evidence would highlight the importance of maintaining an SPI focus in software SMEs, not just for localised improvements in quality or other specific criteria, but for support of business success in the broader sense. In the following section, we outline the structure of the study that we have established in order to examine the relationship between SPI and business success in software SMEs.

\section{Study design}

In this section, we outline the data required to investigate the research hypothesis. We also discuss the overall structure of the study, and present a profile of the participating organisations.

\subsection{Study data components}

In order to investigate the research hypothesis, two distinct areas must be examined: (1) Business Success; and (2) SPI Activity.

\subsubsection{Business success}

The success (or otherwise) of a business is a matter that is open to interpretation. In an earlier related work, the authors provide an overview of the business success domain (Clarke and O'Connor, 2011). There are a variety of different reasons for measuring business success and a variety of different business success measures (Parker, 2000). In the business literature, the term success is used interchangeably with the term performance and in a general sense they both represent the achievement of something desired, planned or attempted (Maidique and Zirger, 1985). However, beyond this general description, controversy exists in relation to what exactly is meant and understood by the term business performance (Morgan and Strong, 2003). Businesses measure performance for a variety of different reasons including, the 
identification of improvement opportunities, determinations in relation to customer satisfaction, to enhance understanding of their own processes and to assess the degree of success achieved (Parker, 2000). This variety of reasons for measuring performance has given rise to a variety of different performance measures that can be classified into one of two groups: financial and non-financial (Hart, 1993).

Traditionally, business success has been measured using purely financial terms (Jennings and Seaman, 1994). However, over recent decades, the acknowledged importance of nonfinancial measures of business success has given rise to multi-dimensional business success frameworks, such as the performance pyramid (Lynch and Cross, 1990), the macro process model (Brown, 1996), Kanji's Business Scorecard (Kanji and Sa, 2002), the performance prism (Neely et al., 2002), and the Balanced Scorecard (BSC) (Kaplan and Norton, 1992). The BSC is considered to be the most popular and influential multidimensional business success measurement framework (Kennerley and Neely, 2002, De Waal, 2003) and in addition to including measures for financial success, the BSC also includes non-financial measures in relation to business processes and customer satisfaction. However, it has been recognised that software development companies have specific characteristics that necessitate an extension of the BSC to include additional measures that are important for software development organisations (Sureshchandar and Leisten, 2005). Hence, the Holistic Scorecard (HSC) (Sureshchandar and Leisten, 2005) was developed as a business success measurement framework for software development organisations. The HSC is composed of six classifications of business objectives: (1) Financial; (2) Customer; (3) Business Process; (4) Employee; (5) Intellectual Capital; and (6) Social. An overview of the HSC (Sureshchandar and Leisten, 2005), including a listing of the sixteen critical success factors associated with each of the six classifications, is presented in Figure 1.

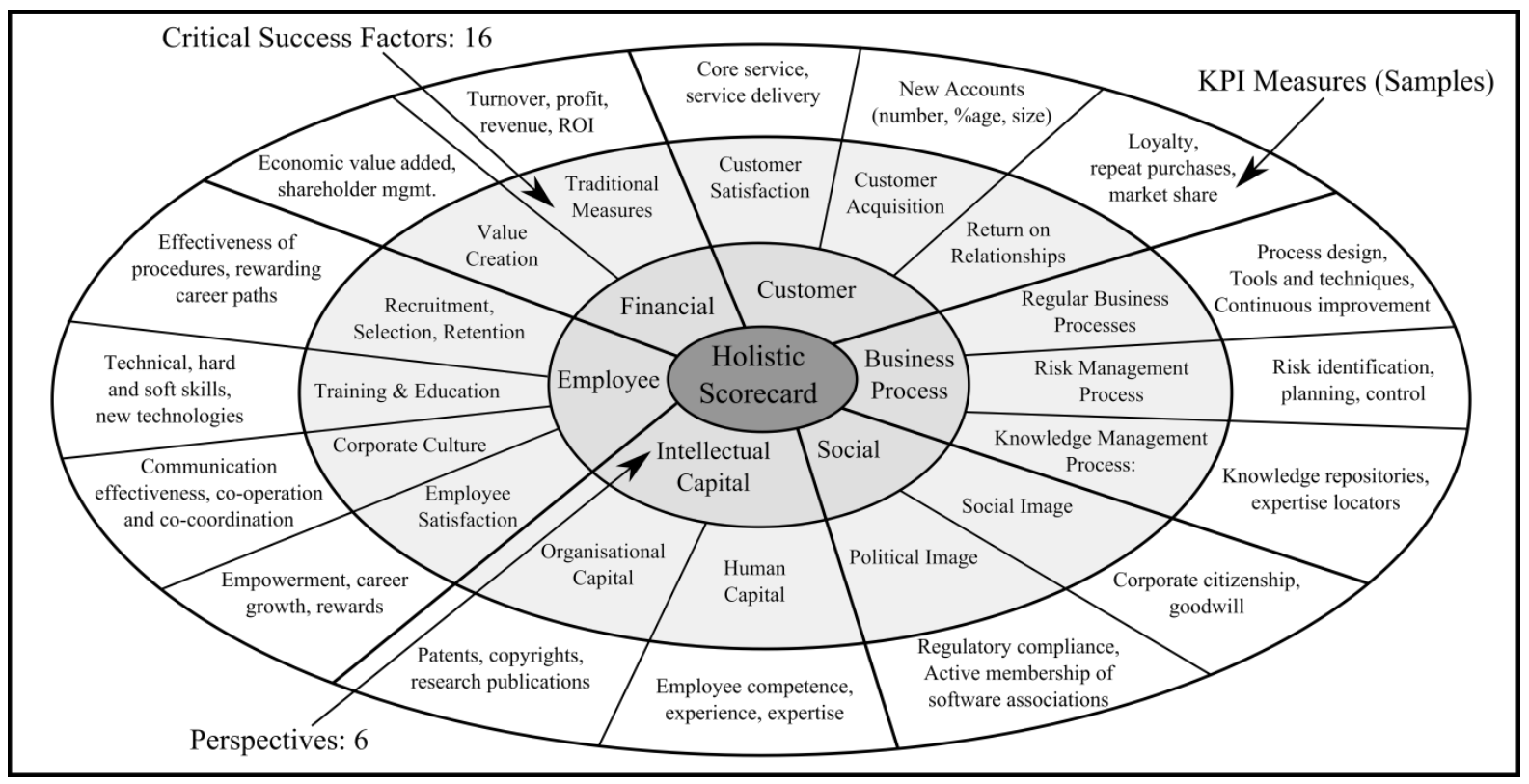

Fig. 1. Holistic Scorecard Overview.

Using the HSC (Sureshchandar and Leisten, 2005) as a reference framework, and applying the scorecard in a manner suitable for SMEs (Andersen et al., 2001), this study gained a thorough view of the broad spectrum of business success parameters applicable to software SMEs. The various success factors and KPIs contained in the HSC (Sureshchandar and Leisten, 2005) were included in a survey instrument consisting of 51 separate questions. Given that some organisations may not formally record business objectives, we introduced a 
two phased business objectives investigation. In the first phase, we discharged the survey instrument to each of the participating organisations in order to elicit the business objectives for the forthcoming year. The second phase of the engagement occurred at the end of the year under investigation, at which time we re-visited the participating organisations and examined the extent to which the recorded objectives were achieved (Clarke and O'Connor, 2011). By formally capturing business objectives at the outset and later examining the extent of their achievement, we minimise any risks related to bias or misrepresentation of achievement on the part of interviewees. Consequently, the two phased approach to examining business success greatly enhances the validity of the business success determinations in this study.

When examining business success in the participating organisations, this study considers success in terms of the extent of achievement of business objectives. The researchers do not undertake to make independent evaluations about which organisations are more successful relative to each other (perhaps according to some selected criteria). For example, it could be possible to examine the success of the organisations relative to the ambition of their stated objectives. Such an examination might reward an organisation that had an objective to grow profit by $100 \%$ more than an organisation that had an objective to grow profit by just $10 \%$. However, there are a number of issues with such an approach. Firstly, since we will deal mostly in percentages, rather than absolute financial measures (a company will report an objective to increase profit by $10 \%$ but they are not likely to be predisposed to disclose the actual financial measure), such an approach could be misleading. For example, a 10\% increase in profit for one company could equate to $€ 1$ million while a $100 \%$ increase in profit for another company could equate to $€ 10,000$. Therefore, it would be inappropriate to evaluate the former organisation more generously than the latter. This limitation applies not just to the financial considerations but also to other business objectives, including, new customer acquisitions and filing for patents or copyrights. A second limitation of such an approach relates to the general subjectivity that would be introduced into the evaluation. Such subjectivity might relate to decisions on how much to reward more ambitious objectives and which objectives might be more important in terms of greater ambition. This degree of subjectivity could act to misrepresent the participating company's view of their own success. Given these limitations, our study opted to evaluate success in terms of the extent to which the company was successful in achieving their own objectives.

\subsubsection{SPI activity}

SPI activity is considered by this study to be the amount of SPI conducted by an organisation over a period of time. When measuring SPI activity it is possible to conduct two process assessments at two separate points in time and thereafter, to conduct a finite difference analysis of the assessment findings. However, process assessments gather data in relation to process maturity and are often used for standards compliance purposes. This study is not concerned with either of these considerations, but rather with SPI activity, and therefore we favour an approach that directly investigates SPI activity in a single engagement with an organisation. As outlined in (Clarke and O'Connor, 2010), there are other benefits to adopting this single-engagement approach: (1) SMEs do not generally perform process assessments and consider them to be a mechanism that is largely the prevail of larger organisations; and (2) Using a twin process assessment approach (and the associated finite difference analysis) to determine the amount of SPI activity would require additional time commitments on the part of the participating organisations, such that it could dissuade them from participating in the study altogether. 


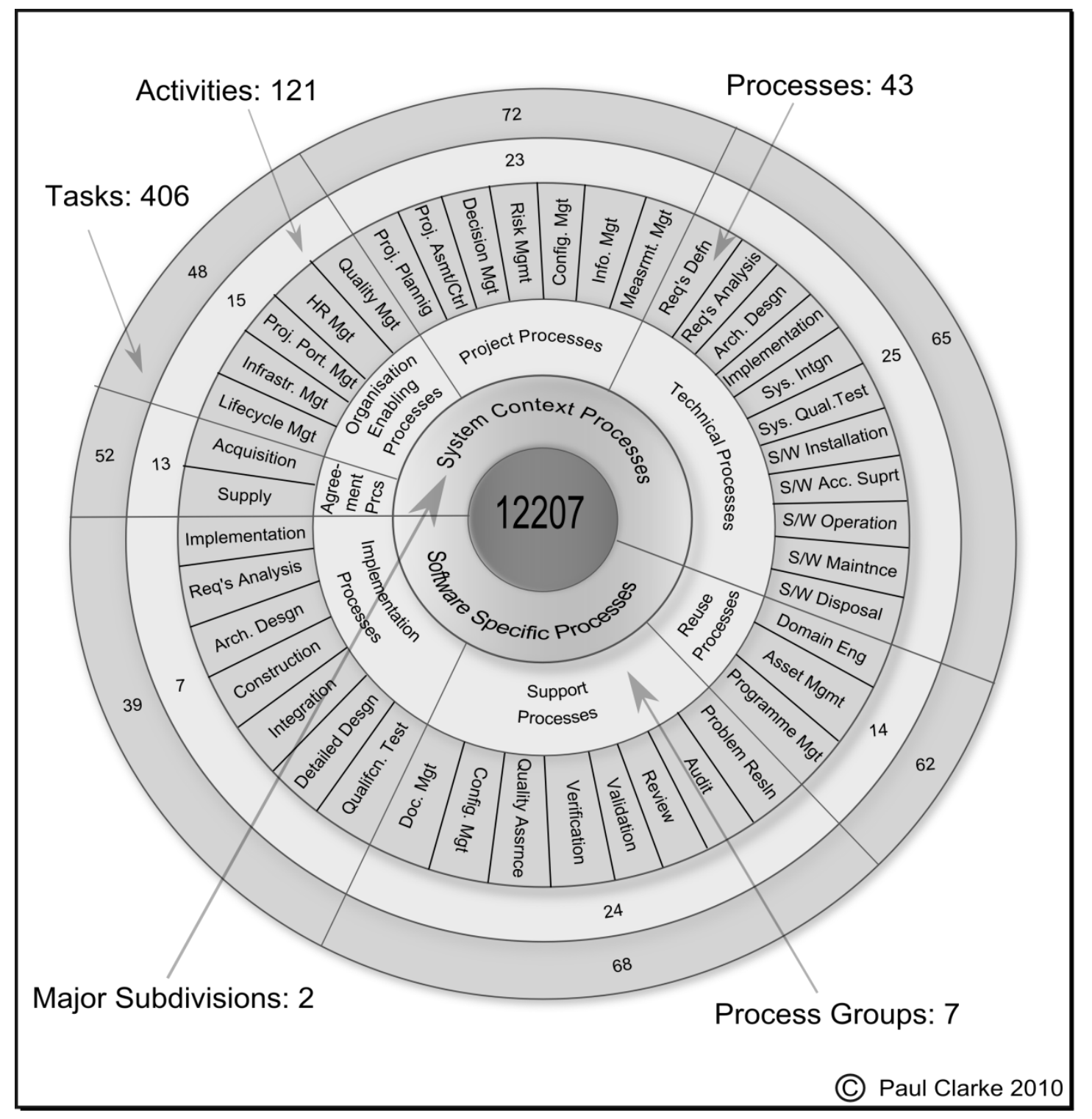

Fig. 2. ISO/IEC 12207 Topology.

In view of these drawbacks associated with using process assessments for examining SPI activity in SMEs, an SPI activity survey instrument that can be discharged in a single engagement was systematically developed using ISO/IEC 12207 (ISO/IEC, 2008) as the underlying reference framework (refer to Figure 2). Furthermore, the SPI activity survey instrument was subjected to review by experts in software processes, including current and former editors of ISO/IEC 12207 (ISO/IEC, 2008). Following consolidation of the expert feedback, the survey instrument was rendered in its final form, now suited to the task of examining the amount of SPI activity in an organisation over a period of time. In this final form, the survey instrument contains 63 individual questions that query the full spectrum of software process activities as contained in ISO/IEC 12207 (ISO/IEC, 2008). Further details on the construction and contents of the SPI activity survey instrument are provided in (Clarke and O'Connor, 2010).

The two survey instruments identified above, the first for business success and the second for SPI activity, are simultaneously discharged to examine the hypothesis set forth in this study. The survey instruments are deployed in a phased fashion over a period of time, as discussed in the following section. 


\subsection{Study timeframe}

Using the survey instruments outlined above, the investigation into the association between business success and SPI activity was discharged over a 16 month period. Initially, the participating organisations were engaged so as to identify their objectives for the forthcoming year. The organisations were revisited 12 months later, at which stage the focus is on determining: (1) the extent to which the recorded objectives were achieved; and (2) the amount of SPI activity undertaken during the 12 month period. These latter engagements with each organisation, coupled with the initial engagement at the commencement of the year under investigation, permit the researchers to undertake a detailed examination of the organisations in the key areas of interest. An overview of the timeline for engaging with the participating organisations is presented in Figure 3.

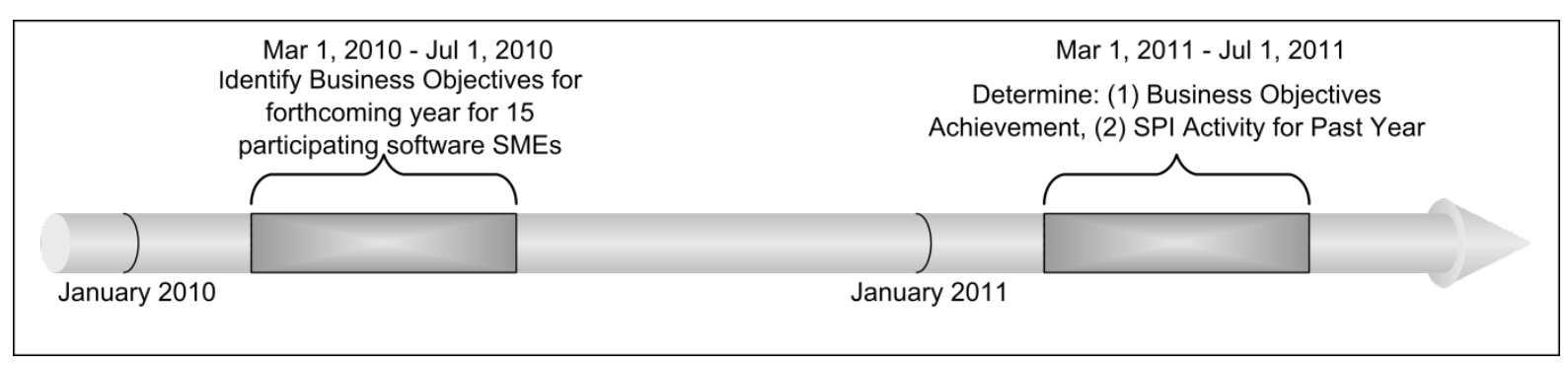

Fig. 3. Research Timeline.

Following each of the initial engagements, the interview recording is used to transcribe the interview, resulting in a documented record for each of the 15 initial engagements. The resulting transcription records include details of the objectives, along with the associated objective ratings. The object ratings, which are described in greater detail in section 4, indicate the importance of the each stated objective.

\subsection{Participating organisations}

The study examined 15 distinct organisations, with the largest recorded headcount being 120, and the lowest recorded headcount being 4. In addition, none of participating organisations had an annual turnover exceeding 50 million euro and/or an annual balance sheet total exceeding 43 million euro. Therefore, all of the participating organisations qualify as micro, small or medium in size (SMEs) under the European Commission's definition (European Commission, 2003 p37). While the majority of the organisations in the study group retained their head office in the Republic of Ireland, a number of the companies are based elsewhere, including locations such as the USA and Chile. Three of the participating companies had less than 10 staff, while 4 of the companies had between 10 and 19 staff. The remainder of the participating organisations had between 20 and 129 staff.

While all of the participating organisations are engaged in software development as their primary business, they operate in different business domains. Four of the organisations develop web-based software, with another four organisations developing software for the telecommunications domain. The remainder of the organisations operate in a variety of different sectors, including, content management, data mediation, and embedded software.

As outlined earlier, the study is concerned with investigating two distinct areas within the participating companies: (1) extent of business success; and (2) the amount of SPI activity. In some cases (predominately the smaller organisations), it was desirable to consult just one 
individual person in order to gather the data in relation to both areas of investigation. However, in other cases, it was necessary to consult more than one individual in a participating firm. While it is logistically challenging and generally more difficult to secure access to multiple personnel in an organisation, there are significant benefits to this type of enquiry. Firstly, since more than one point of view is taken into account, the resultant data can be considered to be more broadly founded and potentially more accurate. Secondly, by getting access to the most informed personnel for a particular consideration, it is possible to get a closer approximation to the truth. This greatly enhances the overall quality of the data with respect to examining the hypothesis set out in this study. In general, the survey questions regarding business success were addressed by Chief Executive Officer (CEO), the Chief Operating Officer (COO), the Managing Director (MD), or the Director of Finance (DF). Questions in relation to the amount of SPI activity were generally answerable by the Director of Engineering (DE), the Chief Technical Officer (CTO), the Engineering Manager (EM), or the Development Manager (DM).

With job titles varying from organisation to organisation (as does the remit and extent of knowledge of the individual undertaking any particular role), one of the initial discussions with each of the participating organisations was aimed at identifying the suitable person(s) to participate in different aspects of the investigation. It's worth noting that gaining access to the range of senior personnel required for this type of study is extremely challenging. In the case of this study, the primary researcher had the benefit of extensive industrial experience which not just facilitated access to the participating organisations, but which it is felt also promoted a candid quality in the feedback; since a cultural insider has the potential to elicit more empathy through an increased perceived understanding of the problem domain. A complete listing of the study participants (by role and company name) is provided in Table 1 . Since some of the areas under investigation are of a confidential nature (e.g. financial performance), it is necessary to allocate a random pseudonym to each of the participating organisations. Therefore, all publications and discussions in relation to the study utilise the pseudonyms rather than the actual company name.

Table 1

Participating Organisations and Personnel

\begin{tabular}{ccc}
\hline Company Pseudonym & Business Success & SPI Activity \\
\hline Silverback & CTO & CTO \\
Grenoble & CEO & EM \\
Mega & MD & MD \\
Cameron & MD & DM \\
Colleran & CEO & CEO \\
\hline Lakes & MD & CTO \\
\hline United & MD & MD \\
Watch & DF, CTO, DE & DE \\
BocaJ & MD & MD \\
Tribal & DE & DE \\
Dynamic & DE & DE \\
Michelin & DE & DM \\
LordHenry & DE & DE \\
When & COO & COO \\
Oryx & COO & DM \\
\hline
\end{tabular}




\subsubsection{Confidentiality and privacy considerations}

In addition to the allocation of random pseudonyms to the participating organisations, a number of additional steps were employed in order to safeguard the confidentiality of the participating organisations, as follows:

- Where deemed appropriate, a bi-lateral non-disclosure agreement (NDA) was established between the research team and the participating organisation;

- All interview recordings and transcriptions were encrypted - this encryption was applied to both the primary and the backup media, and includes data stored on portable recording devices;

- At no stage would the participating organisations be identified, either in documented form or in verbal discussion, to a third party.

Once informed of these confidentiality measures, the participants felt more secure in their contribution, safe in the knowledge that it was being accorded a formal and very high level of confidentiality and security.

\section{Data collection}

As indicated in Figure 3, the data collection took place between March and June 2010, and again between March and June 2011. With two business success interviews required for each of the fifteen participating software SMEs, and a further SPI activity interview also required for each participating organisation, a total of forty five distinct interviews were completed. On average, the total time to interview with each organisation was approximately five hours, giving a total interview time of approximately seventy five hours. For the most part, the interviews were conducted face-to-face; however, in some cases (for example, where the interviewee was based internationally), the interviews were conducted by telephone or videoconference.

As per Figure 3, the first interview focused on identifying the business objectives for the forthcoming year. The associated survey instrument identified business objectives for the forthcoming year, assigning a rating to each of the performance parameters identified in the HSC (Sureshchandar and Leisten, 2005) according to the Likert scale identified in Table 2.

Table 2

Ratings and Interpretations for Business Objectives

\begin{tabular}{cl}
\hline Rating Value & Rating Interpretation \\
\hline 0 & No objective exists \\
1 & A low priority objective exists, but with no explicit target \\
2 & A low priority objective exists, with an explicit target \\
3 & A high priority objective exists, but with no explicit target \\
4 & A high priority objective exists, with an explicit target \\
\hline
\end{tabular}

The scale could have been limited to just three points: high priority, low priority, and no objective. However, it was felt that objectives that had an associated formal target were (1) more easily quantifiable in terms of achievement, and (2), were of a perceived higher importance (since the organisation had gone to the effort of explicitly setting a performance target). Therefore, a five point scale was adopted, within which it was possible to identify objectives that had explicit performance targets. 
Following the completion of the first interview, the interview recording was carefully transcribed. By transcribing the interviews, we ensure that the original description of each objective, as provided by the interviewee, is accurately recorded. This description includes the priority of the objective. For example, a high priority objective to grow the year-on-year profit by $15 \%$ will have a rating value of 4 , while a low priority objective to increase the number of customers but with no expressed explicit target will have a rating value of 1 . Capturing the objectives in this manner permits a later detailed examination of the extent to which the stated objectives were achieved. Once the 12 month period under investigation elapsed, each organisation was revisited, wherein each of the recorded business objectives (from the first interview) was rated in terms of achievement. The achievement of each business objective was rated according to the Likert scale identified in Table 3.

Table 3

Achievement Rating Scale for Business Objectives

\begin{tabular}{cl}
\hline Achievement Value & Achievement Interpretation \\
\hline 0 & Not achieved to any extent \\
1 & Partially achieved \\
2 & Mostly achieved \\
3 & Totally achieved \\
\hline
\end{tabular}

In addition to the business objectives interviews, the extent of SPI activity was also examined, this time using the survey instrument outlined earlier in section 3.1.2. When examining the extent of software process change, modifications to each aspect of the software process were assigned a rating according to the Likert scale identified in Table 4.

Table 4

Modification rating scale for SPI Activity

\begin{tabular}{cl}
\hline Modification Value & Modification Interpretation \\
\hline 0 & No modification \\
1 & Minor modification \\
2 & Moderate modification \\
3 & Significant modification \\
\hline
\end{tabular}

Following the discharge of each survey instrument, the responses of the participants were carefully recorded in electronic form (a task which although time consuming, provides a thoroughly considered and formally recorded record of all key feedback from all participants). Equipped with this carefully collected and recorded data, the next step is to quantifying the data components.

\section{Data component quantification}

For both of the principal data components (extent of business success, and amount of SPI activity), it is necessary to design a representative method for quantification. In the case of the extent of business success, it is necessary to consider two pieces of information: (1) the strength of the original objectives; and (2) the extent of achievement of the objectives. In this research, we have resolved to quantify business success using two separate approaches, which are quantified using two new metrics. These two new metrics are desirable in this study as they facilitate the maximum exploitation of the detailed business success data that was collected in the novel two-phased business success data collection method outlined in section 3.1.1. The first of these two new metrics quantifies business success in terms of the extent of achievement of each of the individual objectives. Under this basic interpretation of 
business success, the measure of success for an organisation is increased each time one of the objectives is achieved to any extent. Furthermore, the achievement of higher rated objectives results in relatively larger increases in the overall success measure. For example, the total achievement of a high priority objective with an explicit target will increase the overall success measure by 4 (4 [value for a high priority objective with an explicit target] x (3 [total achievement value] / 3 [maximum possible achievement value])). In contrast, the total achievement of a low priority objective with no explicit target will increase the overall success measure by 1 (1 [value for a low priority objective with no explicit target] x (3 [total achievement value] / 3 [maximum possible achievement value])). The summing formula for quantifying the overall basic success score is:

$$
\text { BasicBusinessSuccess }=\sum_{i=1}^{N} \text { ObjectiveRating }(i) * \frac{\text { ObjectiveAchievement }(i)}{\text { MaxAchievementValue }}
$$

Where $i$ is an individual business objective, $N$ is the total number of business objective questions (as outlined earlier, there are 51 of business objectives questions), and MaxAchievementValue is 3 (refer to Table 3).

While the basic business success interpretation is useful in measuring the success of an individual organisation, it has a limitation when examining the relative business success across multiple organisations. Since the basic business success interpretation does not have a mechanism for penalising organisations for failure to achieve objectives, it is possible for an organisation with a large number of stated objectives (some of which are not achieved) to appear more successful than another organisation with fewer objectives (all of which are totally achieved). To address this weakness in the basic business success interpretation, we introduced a second approach to quantifying business success.

The second approach to quantifying business success involves the introduction of a weighted negative marking (WNM) scheme. Under this second interpretation, an organisation still receives a weighted score for each objective that is achieved to some extent; however, unlike the basic interpretation, an organisation receives a weighted negative score for each objective that is not achieved or only partially achieved. The benefit of the WNM interpretation is that it facilitates the punitive measure of lowering overall success quantification if there are objectives that are not achieved or only partially achieved. Furthermore, the weighting scheme is designed such that individual weights are in proportion to the strength of the objectives. Applying the WNM scheme outlined in Table 5, the non-achievement of a low priority objective with no specific target will result in a -1 being applied to the overall WMN business success score, whereas the non-achievement of a high priority objective with an explicit target will result in a -4 being applied to the overall WMN business success score.

Table 5

WNM Business Success Scoring Scheme

Strength of Objective

\begin{tabular}{|c|c|c|c|c|c|c|}
\hline \multirow{2}{*}{\multicolumn{2}{|c|}{ Degree of Achievement }} & & & & & \\
\hline & & 0 & 1 & 2 & 3 & 4 \\
\hline 0 & Not achieved & 0 & -1 & -2 & -3 & -4 \\
\hline 1 & Partially achieved & 0 & -0.67 & -1.33 & -2 & -2.67 \\
\hline 2 & Mostly achieved & 0 & 0.67 & 1.33 & 2 & 2.67 \\
\hline 3 & Totally achieved & 0 & 1 & 2 & 3 & 4 \\
\hline
\end{tabular}


With the participating organisations reporting varying numbers of objectives in the first instance, WNM ensures that a company with many objectives cannot score relatively highly unless they are achieving well in most or all objectives. By quantifying business success using WNM, the resultant business success score is considered by the researchers to offer a fairer and more accurate representation of the relative business success of the participating companies - and it is this dimension of relative success that is of primary importance to this study. However, the basic business success score is merited in that it generates a non-adjusted score for the achievement of stated objectives, and therefore, it is also considered to provide a useful measure of business success. Since there are benefits to both interpretations of business success, we have retained both in the study. This allows us to take two separate views of business success, hence improving the reliability of the findings when conducting data analysis and evaluation.

Using the WNM scheme presented in Table 5, the WNM business success score is quantified using the formula:

$$
\text { WNMBusinessSuccess }=\sum_{i=1}^{N} W N M(i)
$$

As with the basic business success score, $i$ is an individual objective, and $N$ is the total number of business objectives questions.

In addition to quantifying business success, the amount of SPI activity must also be determined. In this respect, we examine the broad range of process activities identified in ISO/IEC 12207 (ISO/IEC, 2008), recording instances of reported SPI actions. Where there is a reported SPI action, the interviewee is asked to indicate the extent of the process change according to the modification rating scale identified in Table 4. Using this approach, each individual SPI action is accorded a score, with the total amount of SPI activity being the summation of all process modifications. Therefore, the SPI activity measure can be considered to be representative of the amount of SPI effort undertaken during the period under investigation. SPI activity is calculated according to the following formula:

$$
\text { SPIActivity }=\sum_{j=1}^{M} \text { ModificationValue }(j)
$$

Where $j$ is an SPI activity, and $M$ is the total number SPI activity questions in the survey instrument (as outlined earlier, there are 63 of these SPI questions).

The summing functions outlined above are automated in MS Excel (Microsoft, 2007), wherein the initial data analysis is also conducted. The following section presents the details of the data analysis procedure.

\section{Data analysis}

This section focuses on the data analysis carried out on the study data. Firstly, we outline the initial data analyses that were conducted on the study data. Thereafter, we describe the statistical correlation techniques employed in the data analysis and the associated results. 


\subsection{Data component analysis}

Having conducted a thorough analysis of the business success and SPI activity data, we discovered that there were a number of business objectives and SPI actions that tended to be present more frequently in the participating companies. In relation to the SPI activity, we discovered that the participating software SMEs frequently implemented improvements in the processes for requirements management, configuration management and project planning (reinforcing the findings of a number of earlier studies, including (Sanders and Richardson, 2007)). We also discovered a number of new areas that were frequently targeted for SPI in the participating software SMEs. These new areas included improvements to the software installation process, the software infrastructure management process and the software construction process. In the case of the software installation process, we found that some organisations were increasing the automation of software installation tasks, while in the case of the infrastructure management process we found evidence of a general move towards outsourcing hardware requirements to third parties. This outsourcing could be related to the increased access to hosted hardware solution providers. A comprehensive analysis of all the SPI data collected in this study is available in a related publication (Clarke et al., 2012).

Our analyses also reveal that across the participating organisations, there are certain business objectives that are more commonly reported to be of a high priority. Specifically, we found that the participating organisations consistently had high priority business objectives in six areas: revenue, profit, extension of product offerings, new client acquisitions, repeat business from existing clients and business process management. Growth in revenue was singularly the most significant area for business objectives, followed quite closely by profit targets. Extensions to product offerings also featured as a recurring important objective for the participating companies, with companies often having a clear view on the functionality that they intended to implement over the forthcoming year. Equally, we found that the participating companies had firm and clear objectives in relation to the number of new clients that they intended to acquire. The participating companies also tended to have explicit targets in relation to gaining repeat business from existing clients and in relation to business process improvement. Some of the business process improvements were focused on changes to the sales process, while other business process improvements included changes to the deployment licensing model. In terms of realising the high priority business objectives, we discovered that the participating organisations were most successful at achieving objectives in relation to extensions to product offerings and gaining repeat business from existing clients. The participating organisations were not quite as successful when realising objectives in relation to revenue, profit and business processes; and they were less successful again in terms of achieving targets for new client acquisitions. A comprehensive analysis of the business objectives for the participating organisations is available in a related publication (Clarke and O'Connor, 2011).

\subsection{Relating the data components}

The relationship between any two variables can be illustrated using a scatter graph. A scatter graph is a graph with a scale for each variable and upon which variable values are plotted in pairs, with the basic intention being to visualise whether there is any pattern among the points (Harper, 1991). In this study, we are interested in examining the relationship between business success and SPI activity. Therefore, we initially use scatter graphs to visualise the collected data, so as to get a view as to whether there is a relationship between SPI activity and business success. In Figure 4, the two interpretations of business success, basic and WNM, are plotted along with SPI activity in a scatter graph. 

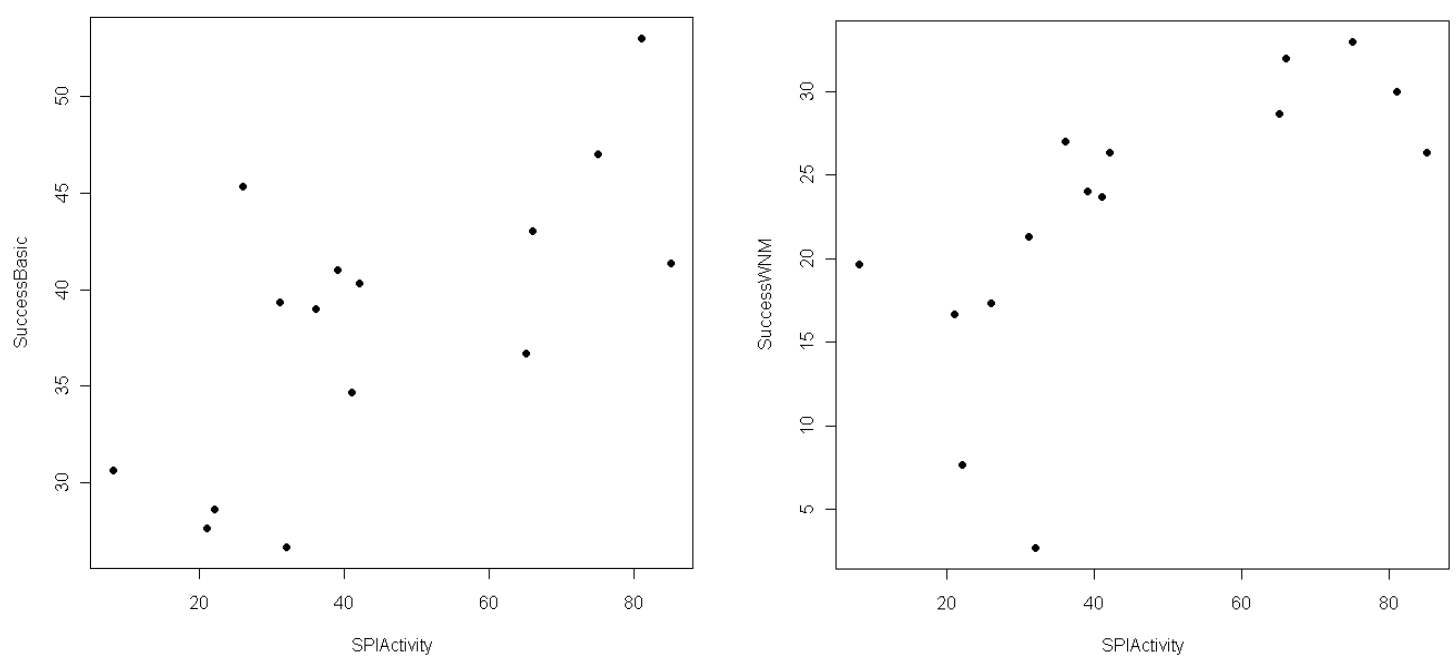

Fig. 4. Scatter Graphs for SPI Activity with Basic and WNM Business Success.

In the case of both scatter graphs in Figure 4, a linear relationship between the two variables can be detected. For example, it can be seen that in general increased SPI activity is tending to present alongside increased basic success. Similarly, higher levels of SPI activity are tending to present in cases where there is also higher WNM business success. Observations such as these indicate that there is a positive linear relationship between business success (both basic and WNM) and SPI activity - however, while scatter graphs permit a visualisation of patterns in the data, they are limited insofar as they lack a measure of the closeness of the relationship between the plotted variables (Harper, 1991). Correlation analysis provides a measure of the closeness of the relationship between variables (Reilly, 1997). Therefore, the next step in the analysis is therefore to perform some standard statistical correlations on the data.

\subsection{Data correlations}

In order to express quantitatively the extent to which two variables are related, it is necessary to calculate a correlation coefficient (Haber and Runyon, 1980). A number of different correlation coefficients exist, and when choosing a the appropriate correlation technique, a number of factors should be considered, including (1) the type of scale of measurement in which the variables are measured, and (2) the nature of the distribution of the underlying data (Haber and Runyon, 1980).

This study predominately uses ordinal measurement scales, such as the Likert scales in Tables 2, 3 and 4. On an ordinal data scale, the numbers that are assigned to variables express a "greater than" relationship, but they do not indicate "how much greater" (Kranzler, 2003). Therefore, points on an ordinal scale indicate a ranking but they do not necessarily have equal units of measurements. This is different from interval or measurement scales (Koopmans, 1981) (for example, using a metre scale to measure height) where the numbers that are assigned to variables reflect relative merit and have equal units of measurement. In the absence of equal units of measurement, it is advisable to use a ranked correlation coefficient, such as the Spearman coefficient (generally designated as $R$ ) (Hinton, 1995). Therefore, the Spearman coefficient is employed as the primary correlation coefficient for this study. 
While it is generally recommended that ranked correlations are applied to ordinal data (Hinton, 1995), such as the data utilised in this study, there are claims that it is permissible to perform interval data correlation techniques on ordinal data (O'Brien, 1979), especially in cases where the underlying data is normally distributed (the distribution for the variable is bell-curved in shape (Harper, 1991)). The most common interval data correlation technique is the Pearson product-moment correlation co-efficient (generally designated as $r$ ) (Kranzler, 2003). Since the data in this study is normally distributed, and considering that Pearson product-moment correlation coefficients are considered to be more precise than Spearman ranked correlation coefficients (Harper, 1991), we also conduct Pearson product-moment correlations on the study data.

The possible values of correlation coefficients range from +1.00 to -1.00 . The closer the correlation coefficient is to +1.00 or -1.00 , the closer the relationship between the variables; and the closer the correlation coefficient is to 0, the less close the relationship (Harper, 1991). One further important aspect of correlation coefficients concerns the probability value ( $p$ value). The p-value indicates the odds of a chance occurrence (Hinton, 1995), or in other words, the probability of an error when making declarations in relation to the significance of the correlation coefficient.

The correlation coefficients for SPI activity and business success, calculated and crosschecked in Statistica (StatSoft, 2007) and $R$ (The R Project, 2011), are presented in Table 6.

Table 6

Spearman and Pearson Correlation Coefficients

\begin{tabular}{|c|c|c|c|}
\cline { 3 - 4 } \multicolumn{2}{c|}{} & $\begin{array}{c}\text { SPI Activity \& } \\
\text { Basic Business Success }\end{array}$ & $\begin{array}{c}\text { SPI Activity \& } \\
\text { WNM Business Success }\end{array}$ \\
\hline \multirow{2}{*}{ Spearman } & R & 0.66 & 0.81 \\
\cline { 2 - 4 } & p-value & 0.009 & $0.0002^{*}$ \\
\hline \multirow{2}{*}{ Pearson } & $\mathrm{r}$ & 0.68 & 0.68 \\
\cline { 2 - 4 } & $\mathrm{p}$-value & 0.005 & 0.005 \\
\hline
\end{tabular}

Examining the Spearman and Pearson correlation coefficients for business success (both basic and WNM) and SPI activity, we find that the coefficients range from 0.66 to 0.81 (refer to Table 6). This indicates that there is a positive correlation between SPI activity and business success. Additionally, when taking the sample size, the correlation coefficients and the p-values into consideration, we can declare that the correlation coefficients are statistically significant (refer to Appendix A.9 and A.10 in Hinton (1995) for a breakdown on the interpretation of significance). Additional variations on the correlations reported herein were also conducted on the data in order to perform a sensitivity analysis on the results. For example, it is possible that there are areas of overlap across some aspects of the HSC-based business process objectives and ISO/IEC 12207 processes; including such areas as risk and knowledge management. Therefore, these particular objectives (along with other potentially overlapping HSC business process objectives) were removed from the business objectives

\footnotetext{
* Spearman correlation p-values cannot necessarily be reliably computed where a variable has the same value for two separate cases. In the case of this study, the participating organisations Cameron and Michelin both got a WNM Business Success score of 26.33. Hence, the Spearman p-value calculation is marginally compromised when correlating SPI Activity and WNM Business Success.
} 
data and the correlations were preformed on the resulting data suites. The results of these additional correlations demonstrate that SPI activity and business success continue to be positively correlated even when the potentially overlapping areas are removed from the HSC data (these additional correlations produce statistically significant Spearman and Pearson correlation coefficients ranging from 0.56 to 0.75 ).

In light of the data analyses outlined above, this research supports the hypothesis that increased SPI is positively associated with increased business success. Furthermore, the correlations between SPI activity and business success range from 0.66 to 0.81 , suggesting that these two phenomena are not just positively correlated, but they are in fact tending towards being strongly positively correlated. At 0.81 , the Spearman correlation coefficient for WNM business success and SPI is strong. This correlation is particularly interesting, as the WNM interpretation is considered by the researchers to present the fairest interpretation of the relative business success in the participating organisations (as discussed in section 5). The following section, Discussion, explores the meaning and impact of these findings.

\section{Discussion}

As outlined in the preceding sections, we have employed standard correlation techniques to examine the strength of the relationship between SPI activity and business success. The correlations conducted in this study compare the organisations in terms of their relative amounts of SPI activity and business success, finding that those organisations conducting relatively higher amounts of SPI activity also tend to record relatively higher amounts of business success. While members of the software process and SPI communities may not be surprised by these findings, earlier research suggests that in practice, companies may not place a high priority on the software process (Baddoo and Hall, 2003), with software SMEs only implementing process improvements in response to negative business events (Coleman and O'Connor, 2008). Since the evidence provided in this study indicates, for the first time, that there is a positive correlation between increases in SPI and increases in business success, the motivation for conducting SPI in software SMEs is improved.

The hypothesis set out in this study essentially seeks to examine the relationship between increased SPI activity and business success in software SMEs. Since general business process management theory and practice inform us of the importance of maintaining effective business processes (McCormack and Johnson, 2001, Skrinjar et al., 2008, Kaplan and Norton, 1992, Neely et al., 2002), and seeing as the needs of many businesses are continually changing, we should therefore expect that software SMEs with a stronger SPI focus should, in general, tend to be more successful. Nonetheless, it is worth briefly examining the possibility that it was the increased business success that gave rise to increases in SPI activity.

In our study, those companies that reported relatively higher levels of business success were also reporting relatively higher amounts of SPI activity. However, if we consider that SPI is concerned with improving the software development process to best support the business needs, then SPI should not just be implemented in companies presenting with higher levels of business success - we should expect to also observe evidence of increased levels of SPI activity in some of the companies that are performing poorly; since a decline in the fortunes of an organisation is just as likely to be a catalyst for process change. Such evidence is weak in our study, with the general observable trend being that companies with relatively lower levels of success also having relatively lower levels of SPI activity (refer to Figure 4). 
However, the evidence is not conclusive in this respect, with for example, two of the lesser successful organisations (under the WNM interpretation) reporting moderate levels of SPI activity when compared with the other participating organisations. These two organisations can be considered to be outliers in terms of the general observable trend and therefore, although in general, the data collected in this study suggests that it is not the case that increases in business success are giving rise to increases in SPI activity, further evidence would be required in order to establish a conclusive position in this regard.

Another interesting finding from the study is that although different amounts of SPI are being performed in the participating organisations, without exception all of the participating software SMEs implemented some SPI activity over the study period. While some of the organisations only performed small amounts of SPI, the fact that all of the participating organisations performed some degree of SPI suggests that the software process is not fixed but rather that the process in continually changing, even if only modestly. This particular finding supports the argument that no one size fit all when it comes to software development processes (Boehm and Turner, 2003) and that process adaptation is an important activity for software development companies (Poulin, 2007). If we accept that the software development process is continually changing in organisations, then valuable future research should focus on profiling the impact of situational change on aspects of the software development process. In particular, it would be useful to better understand the interplay between situational changes and software process changes, perhaps developing a relational mapping between aspects of the software development process and aspects of the (changing) situation.

While our study has identified a positive association between SPI activity and business success, it is important top highlight that a software development business can be successful for a host of reasons, not all of which are related to SPI. For example, the business can be successful because of the talent of its individuals, its commitment to quality and general business accountability (McConnell, 2012). These particular considerations are not directly related to SPI - though they could result in SPI activity. Therefore, in our study it is possible that the talent of individuals or the commitment of the employees to quality or the quality of the management team in the participating organisations were the primary drivers for business success rather than the distinct activity of SPI that we have examined in this research. Future valuable research could examine the influence of these primary drivers on SPI activity. It should also be noted that the full benefit of some SPI activity can take many years to be realised and therefore, the SPI implemented in the study timeframe may not in itself impact on the business success in the timeframe under examination, rather it is indicative of the desire or capability of the organisation to implement SPI on an ongoing basis. However, the absence of SPI data from earlier periods in the existence of the participating organisations does introduce a threat to the validity of our findings.

\subsection{Study limitations}

We have also identified a number of limitations in the study. Firstly, we identify a limitation in relation to the reference frameworks employed in the study. While the HSC (Sureshchandar and Leisten, 2005) and ISO/IEC 12207 (ISO/IEC, 2008) represent substantial frameworks for business success and software development processes, it must be acknowledged that no framework is absolutely complete. Therefore, it is possible that aspects of business success and software development processes exist beyond the scope of the HSC and ISO/IEC 12207. Since these are the most comprehensive frameworks available at this time and, given the scale of the frameworks, it is unlikely that significant aspects of business success or of the software development process have been overlooked. However, in particular 
in relation to ISO/IEC 12207, it is important to highlight that there may be dimensions of the software development process that are beyond the strict confines of the process reference standard. For example, although there is some direction on the mapping between agile software development and ISO/IEC 12207 (Pikkarainen, 2006), certain agile software development practices may not neatly align with the processes in ISO/IEC 12207.

A second limitation relates to the new metrics that were introduced in this study, namely $S P I$ Activity, BasicBusinessSuccess and WNMBusinessSuccess. These metrics have served this particular study well; however, their broader utilisation in future research may require that additional metric validation is conducted so as to ensure that they address the wider needs of other research and practitioner application. In this study, these new metrics were calculated for each of the participating organisations using data collected from the study participants and while every effort was taken to carefully elicit the data, a possible threat to validity concerns the subjectivity of the individual participants when responding to the queries. Broader utilisation of the data collection and metrics introduced in this study would aid our understanding of the general utility of these new approaches.

A third limitation relates to the number of participating organisations. While this study involved accessing a variety of key, strategic, and busy personnel in fifteen participating SMEs - and such access is very difficult to orchestrate - the sample size is not particularly large from a numerical perspective. Nonetheless, a significant depth of information has been gathered and the sample size is large when compared to similar studies in this domain. Furthermore, the correlations reported herein are statistically significant under standard significance interpretations (which take the sample size into consideration when calculating significance measures). However, a similar study incorporating a larger number of participating software SMEs could expect to make stronger claims in relation to the generalisability of findings - and perhaps this is an area worth considering for future research.

\subsection{Future research}

Other future research could also examine the relationship between business objectives and the software development process. While software development teams and software business managers can sometimes appear to operate with different objectives, it is important for both parties to recognise that there is a large degree of symbiosis in their respective goals. Consequently, software development efforts should support the business in achieving its success, while at the same time the business should support the software development team in producing high quality software in a sustainable fashion. Therefore, important future research should examine different approaches to improving the awareness of both the business and the software process needs across the business as a whole; and efforts to harmonise these sometimes conflicting needs would appear to offer benefits for both developers and managers. In this respect, perhaps software development undergraduate programmes could be extended to provide students with a basic understanding of the essential business needs in software development companies. In this respect, the authors recommend the HSC (Sureshchandar and Leisten, 2005) as a valuable resource.

The authors also plan additional work in terms of further analysing the data captured in this study. This future work will examine the reported process improvements, paying particular attention to the commonalities and differences reported in the participating companies. We expect that this will confirm some of the findings from earlier related studies, but also hope 
that we may discover some new information regarding the type and profile of process improvements that are being implemented in software SMEs.

\section{Conclusion}

In this research, fifteen software SMEs have been engaged in a sixteen month long study. Over the study period, the business success of each of the software SME has been tracked. In parallel to the business success investigation, the study has also examined the amount of SPI activity in the software SMEs. The purpose of the research was to examine the hypothesis that increases in SPI activity are positively associated with increases in business success. As outlined in the earlier sections, the findings of this empirical study support this hypothesis (through the use of new metrics to quantify SPI activity and business success).

As with all studies involving statistical correlation, it is important to highlight the risk of interpreting the results as evidence of a cause-and-effect relationship between variables. Correlation is not concerned with cause-and-effect but rather, correlation merely indicates the extent to which variables are co-related. Therefore, we can not and should not suggest that increases in SPI alone will result in increased business success - since the very nature of statistical correlation does not permit for such conclusions. Furthermore, it is rather obvious that factors other than SPI also have an important influence on business success (e.g. the effectiveness of the sales team in delivering revenue to the company). While correlation cannot make determinations in relation to cause-and-effect, the existence and strength of the correlation evidenced in this study supports the argument that SPI is a factor that can influence the business success of software SMEs. It is the view of the authors that evidence of this nature will encourage greater focus on the software development process in software SMEs.

Some of the earlier studies investigating SPI in software SMEs have examined the benefits of individual process improvements (Kautz, 1998, Sanders, 1998, Von Wangenheim et al., 2006), such as improvements in testing giving rise to improvements in product quality. Other earlier studies have reported on the positive outcomes following the adoption of SPI frameworks (Anacleto et al., 2004, Cepeda et al., 2008, Leung and Yuen, 2001). While these earlier studies are of immense value to SPI researchers and practitioners, they don't necessarily provide the type of evidence that is required in order to promote a strong and sustained software process management focus in software SMEs. Hence, it has been reported that senior business managers can lack a commitment to SPI (Baddoo and Hall, 2003).

Unlike earlier studies into the benefits of SPI in software SMEs, the study presented herein has examined the general relationship between relatively higher levels of SPI activity and business success. Furthermore, by using the HSC (Sureshchandar and Leisten, 2005) as the reference framework for examining business success, we don't just employ financial measures of success but we also consider the broader spectrum of non-financial measures that are important performance criteria for software development organisations.

This is the first study of this nature and the findings are consistent with established theory in relation to the importance of business process management. Specifically, in relation to the software process, the findings of this study indicate that within the fifteen participating organisations, SPI activity and business success are positively associated. The authors consider this to be a valuable new insight into the importance of SPI in successful software SMEs. This new insight suggests that in software SMEs, the continuous application of SPI 
may have a role to play in supporting the achievement of business objectives. Therefore, it may be advantageous to implement SPI on a regular basis, rather than in an irregular, chaotic or reactive fashion as has been reported in earlier studies (Coleman and O'Connor, 2008). The evidence presented in this research can help to increase the focus on the software process and the commitment of senior managers to SPI initiatives in software SMEs, and in so doing, can help software SMEs to be more successful.

\section{Acknowledgements.}

This work was supported, in part, by Science Foundation Ireland grant 03/CE2/I303_1 to Lero - the Irish Software Engineering Research Centre (www.lero.ie).

The authors would like to thank Prof. Brian Leavy, Dublin City University Business School (www.dcu.ie/dcubs) for his advice regarding the structure of business success investigations.

\section{References}

Anacleto, A., Von Wangenheim, C.G., Salviano, C.F., Savi, R., 2004. Experiences Gained from Applying ISO/IEC 15504 to Small Software Companies in Brazil. In: 4th International Conference on Process Assessment and Improvement. SPICE User Group, Buckinghamshire, U.K., pp. 33-37.

Andersen, H., Cobbold, I., Lawrie, G., 2001. Balanced Scorecard implementation in SMEs: reflection in literature and practice. In: Proceedings of the fourth SMESME Conference. Department of Production, 2GC Limited. Aalborg University, 9220 Aalborg, Denmark, pp. 103-112.

Baddoo, N., Hall, T., 2003. De-motivators for software process improvement: an analysis of practitioners' views. Journal of Systems and Software 66 (1), 23-33.

Biro, M., Ivanyos, J., Messnarz, R., 2000. Pioneering Process Improvement Experiment in Hungary. Software Process: Improvement and Practice 5 (4), 213-229.

Boehm, B., Turner, R., 2003. Balancing Agility and Discipline - A Guide for the Perplexed. Pearson Education Limited, Boston, Massachusetts, USA.

Brown, M.G., 1996. Keeping Score: Using the Right Metrics to Drive World-Class Performance. Quality Resources, New York, USA.

Cater-Steel, A., Rout, T., 2008. SPI Long-Term Benefits: Case Studies of Five Small Firms. In: Oktaba, H., Software Process Improvement for Small and Medium Enterprises Techniques and Case Studies. IGI Global, Hershey, PA, USA.

Cepeda, S., Garcia, S., Langhout, J., 2008. Is CMMI Useful and Usable in Small Settings? CrossTalk, The Journal of Defense Software Engineering 21 (2), 14-18.

Clarke, P., O'Connor, R., 2010. Harnessing ISO/IEC 12207 to examine the extent of SPI activity in an organisation. In: Proceedings of the 17th Conference on European Systems \& Software Process Improvement and Innovation (EuroSPI2010). Springer-Verlag, CCIS 99/2010. Heidelberg / Berlin, Germany, pp. 25-36.

Clarke, P., O'Connor, R.V., 2011. The Meaning of Success for Software SMEs: An Holistic Scorecard Based Approach. In: Proceedings of the 18th International Conference on Systems, 
Software and Services Process Improvement (EuroSPI 2011). Springer-Verlag, Heidelberg / Berlin, Germany, pp. 72-83.

Clarke, P., O'Connor, R.V., Yilmaz, M., 2012. A Hierarchy of SPI Activities for Software SMEs: Results from ISO/IEC 12207-Based SPI Assessments. To appear in: Proceedings of the 12th International Conference on Software Process Improvement and capability dEtermination (SPICE 2012). Springer-Verlag, Berlin Heidelberg, Germany, pp. 62-74.

Coleman, G., O'Connor, R., 2008. Investigating software process in practice: A grounded theory perspective. Journal of Systems and Software 81 (5), 772-784.

Cugola, G., 1998. Tolerating deviations in process support systems via flexible enactment of process models. IEEE Transactions on Software Engineering 24 (11), 982-1001.

De Waal, A. A., 2003. Behavioural factors important for the successful implementation and use of performance management systems. Management Decision 41 (8), 688-699.

Deephouse, C., Goldenson, D., Kellner, M., Mukhopadhyay, T., 1995. The effects of software processes on meeting targets and quality. In: Proceedings of the 28th Annual Hawaii International Conference on System Sciences (HICSS 1995). IEEE Computer Society, Los Alamitos, California, USA, pp. 710-719.

El Emam, K., Birk, A., 2000. Validating the ISO/IEC 15504 measures of software development process capability. Journal of Systems and Software 51 (2), 119-149.

Erdogmus, H., Favaro, J., Strigel, W., 2004. ROI in the Software Industry - Return on Investment - Guest Editors' Introduction. IEEE Software 21 (3), 18-22.

European Commission, 2003. Commission Recommendation of 6 May 2003 concerning the definition of micro, small and medium-sized enterprises. 2003/361/EC. Official Journal of the European Union L (124), 36-41.

Ferreira, A.I.F., Santos, G., Cerqueira, R., 2007. Applying ISO 9001:2000, MPS.BR and CMMI to Achieve Software Process Maturity: BL Informatica's Pathway. In: Proceedings of the 29th International Conference on Software Engineering (ICSE 2007). IEEE Computer Society, Los Alamitos, California, USA, pp. 642-651.

Fleck, D., 2004. A Process for Very Small Projects. In: Proceedings of the 22nd Annual Pacific Northwest Software Quality Conference. PNSQC/Pacific Agenda, Portland, Oregon, USA, pp. 107-115.

Haber, A., Runyon, R., 1980. General Statistics. Edition 3rd. Addison-Wesley Publishing Company, Inc., Boston, Massachusetts, USA.

Harper, W., 1991. Statistics. Edition 6th. Pitman Publishing, 128 Long Acre, London, U.K.

Hart, S., 1993. Dimensions of Success in New Product Development: an Exploratory Investigation. Journal of Marketing Management 9 (1), 23-41.

Hinton, P., 1995. Statistics Explained: A guide for social science students. Edition 1st. Routledge, London, United Kingdom. 
ISO, 2004. ISO 9003:2004 - Software Engineering - Guidelines for the application of ISO 9001:2000 to computer software. ISO, Geneva, Switzerland.

ISO/IEC, 2008. ISO/IEC 12207-2008 - Systems and software engineering - Software life cycle processes. ISO, Geneva, Switzerland.

Jennings, D. F., Seaman, S. L., 1994. High and low levels of organizational adaptation: An empirical analysis of strategy, structure, and performance. Strategic Management Journal 15 (6), 459-475.

Kanji, G. K., Sa, P. M., 2002. Kanji's Business Scorecard. Total Quality Management 13 (1), $13-27$.

Kaplan, R. S., Norton, D. P., 1992. The Balanced Scorecard - Measures That Drive Performance. Harvard Business Review 70 (1), 71-79.

Kautz, K., 1998. Software process improvement in very small enterprises: does it pay off? Software Process: Improvement and Practice 4 (4), 209-226.

Kennerley, M., Neely, A., 2002. Performance Measurement Frameworks: A Review. Cambridge University Press, IN: Business Performance Measurement - Theory and Practice. Cambridge, UK.

Koopmans, L., 1981. An introduction to contemporary statistics. Edition 1st. PWS Publishers, Belmont, CA, USA.

Kranzler, J., 2003. Statistics for the Terrified. Edition 3rd. Prentice Hall, Upper Saddle River, NJ, USA.

Leung, H. K. N., Yuen, T. C. F., 2001. A process framework for small projects. Software Process: Improvement and Practice 6 (2), 67-83.

Lynch, R.L., Cross, K.F., 1990. Measure Up! Yardstick for Continuous Improvement. Basil Blackwell, Cambridge, Massachusetts, USA.

Maidique, M. A., Zirger, B. J., 1985. The new product learning cycle. Research Policy 14 (6), 299-313.

Mathiassen, L., Ngwenyama, O. K., Aaen, I., 2005. Managing change in software process improvement. IEEE Software 22 (6), 84-91.

McConnell, S. 2011. GTAC 2011 Closing Keynote: Secrets of World Class Software Organisations [Online]. Available from: < $\underline{\text { www.youtube.com } / w a t c h ? v=E E-t 5 J 7 h n H E}>$ [Accessed 03/27 2012].

McConnell, S., 2002. Closing the gap. IEEE Software 19 (1), 3-5.

McCormack, K., Johnson, W., 2001. Business Process Orientation - Gaining the E-Business Competitive Advantage. CRC Press, Florida, USA.

Microsoft, Excel. Version 2007. Available from: www.microsoft.com. 
Miluk, G., 2005. Results of a field study of CMMI for small settings using rapid applied ethnography. In: Proceedings of the 1st International Research Workshop for Process Improvement in Small Settings. Software Engineering Institute, Carnegie Mellon University, CMU-SEI-2006-SR-001. Pittsburgh, Pennsylvania, USA, pp. 27-38.

Morgan, R. E., Strong, C. A., 2003. Business performance and dimensions of strategic orientation. Journal of Business Research 56 (3), 163-176.

Neely, A.D., Adams, C., Kennerley, M., 2002. The Performance Prism: the scorecard for measuring and managing business success. Prentice Hall, London, United Kingdom.

Niazi, M., 2006. Software Process Improvement: A Road to Success. In: Proceedings of the 7th International Conference on Product Focused Software Process Improvement. Springer, LNCS 4034/2006. Berlin / Heidelberg, Germany, pp. 395-401.

Niazi, M., Babar, M. A., 2009. Identifying high perceived value practices of CMMI level 2: An empirical study. Information and Software Technology 51 (8), 1231-1243.

Niazi, M., Babar, M.A., Ibrahim, S., 2008. An Empirical Study Identifying High Perceived Value Practices of CMMI Level 2. In: Proceedings of the 9th International Conference on Product Focused Software Process Improvement. Springer-Verlag, LNCS 5089/2008. Berlin / Heidelberg, Germany, pp. 427-441.

O'Brien, R., 1979. The Use of Pearson's with Ordinal Data. American Sociological Review 44 (5), 851-857.

Pall, G., 1987. Quality Process Management. Prentice Hall, Englewood Cliffs, NJ, USA.

Parker, C., 2000. Performance Measurement. Work Study 49 (2), 63-66.

Pikkarainen, M., 2006. Mapping Agile Software Development onto ISO 12207. Agile Consortium, Published online at www.agile-itea.org.

Pino, F. J., Garcia, F., Piattini, M., 2008. Software process improvement in small and medium software enterprises: a systematic review. Software Quality Journal 16 (2), 237-261.

Poulin, L. A., 2007. Achieving the Right Balance Between Process Maturity and Performance. IEEE Canadian Review 56 (-), 23-26.

Reilly, J., 1997. Understanding Statistics. Edition 1st. Folens Publishers, Dublin, Ireland.

Rico, D.F., 2004. ROI of Software Process Improvement: Metrics for Project Managers and Software Engineers. J. Ross Publishing, Fort Lauderdale, Florida, USA.

Rozum, J.A., 1993. Concepts on Measuring the Benefits of Software Process Improvements. Software Engineering Institute, Carnegie Mellon University, CMU/SEI-93-TR-009. Pittsburgh, Pennsylvania, USA.

Sanders, M., 1998. The SPIRE Handbook. Better, Faster, Cheaper Software Development in Small Organisations. Centre for Software Engineering Limited, DCU, Dublin, Ireland. 
Sanders, M., Richardson, I., 2007. Research into long-term improvements in small- to medium-sized organisations using SPICE as a framework for standards. Software Process: Improvement and Practice 12 (4), 351-359.

Scott, L., Carvalho, L., Jeffery, R., D'Ambra, J., Becker-Kornstaedt, U., 2002. Understanding the use of an electronic process guide. Information and Software Technology 44 (10), 601616.

SEI, 2006. CMMI for Development, Version 1.2. Software Engineering Institute, CMU/SEI2006-TR-008. Pittsburgh, PA, USA.

Skrinjar, R., Bosilj-Vuksic, V., Indihar-Stemberger, M., 2008. The impact of business process orientation on financial and non-financial performance. Business Process Management Journal 14 (5), 738-754.

StatSoft, Statistica. Version 8. Available from: www.statsoft.com.

Sureshchandar, G. S., Leisten, R., 2005. Holistic Scorecard: strategic performance measurement and management in the software industry. Measuring Business Excellence 9 (2), 12-29.

The R Project, R. Version 2.08. Available from: www.r-project.org.

Van Solingen, R., 2004. Measuring the ROI of Software Process Improvement. IEEE Software 21 (3), 32-38.

Vergidis, K., Tiwari, A., Majeed, B., 2008. Business Process Analysis and Optimization: Beyond Reengineering. IEEE Transactions on Systems, Man, and Cybernetics, Part C: Applications and Reviews 38 (1), 69-82.

Von Wangenheim, C. G., Weber, S., Hauck, J. C. R., Trentin, G., 2006. Experiences on establishing software processes in small companies. Information and Software Technology 48 (9), 890-900.

Zahran, S., 1998. Software process improvement: practical guidelines for business success. Pearson Education Limited, Harlow, Essex, UK.

Paul Clarke received the BSc Hons degree from Dublin City University in 1996 and has accrued 12 years of industrial software development experience in a variety of sectors, including telecommunications, internet and insurance. Paul was awarded a Lero Graduate School in Software Engineering (LGSSE) research scholarship in 2008 and is presently in the third year of his $\mathrm{PhD}$ research. His research interests include software processes, software development methodologies and standards, software process improvement, economics of software engineering and team dynamics.

Dr. Rory V. O'Connor is a Senior Lecturer in Software Engineering at Dublin City University and a Senior Researcher with Lero, The Irish Software Engineering Research Centre. He has previously held research positions at both the National Centre for Software Engineering and the Centre for Teaching Computing, and has also worked as a software engineer and consultant for several European technology organizations. He is also Ireland's 
Clarke, P. and O'Connor, R., The influence of SPI on business success in software SMEs: An empirical study, Journal of Systems and Software, Vol. 85, No. 10, 2012. Pages 2356-2367

Head of delegation to ISO/IEC JCT1/SC7. His research interests are centered on the processes whereby software intensive systems are designed, implemented and managed. 